\title{
Lignin-containing Feedstock Hydrogenolysis for Biofuel Component Production
}

\author{
Elena I. Shimanskaya ${ }^{*}$, Antonina A. Stepacheva1, Esther M. Sulman ${ }^{1}$, \\ Evgeny V. Rebrov ${ }^{1,2}$, Valentina G. Matveeva ${ }^{1,3}$ \\ ${ }^{1}$ Department of Biotechnology and Chemistry, Tver State Technical University, \\ Tver, 170026, Russia \\ ${ }^{2}$ School of Engineering, University of Warwick, Coventry, CV4 7AL, United Kingdom \\ ${ }^{3}$ Regional Technological Center, Tver State University, Tver,170100, Russia
}

Received: $3^{\text {rd }}$ March 2017; Revised: $18^{\text {th }}$ August 2017; Accepted: $21^{\text {st }}$ August 2017

Available online: 22 ${ }^{\text {nd }}$ January 2018; Published regularly: $2^{\text {nd }}$ April 2018

\begin{abstract}
In this paper, the commercial $5 \% \mathrm{Pd} / \mathrm{C}$ and $5 \% \mathrm{Pt} / \mathrm{C}$ catalysts and synthesized $5 \% \mathrm{Pt} / \mathrm{MN}-270$ and $5 \% \mathrm{Pd} / \mathrm{MN}-270$ were used in the hydrogenolysis of lignocellulosic material (softwood sawdust) to obtain liquid fuels in the form of hydrocarbons. As lignin has a very complex structure, anisole was used as a model compound. It was found that the use Pt-containing catalysts based on hypercrosslinked polystyrene in both processes of anisole and lignin-containing feedstock conversion allowed obtaining the highest yield of oxygen-free hydrocarbons (up to 96 wt. \%). Besides, the polymer based catalysts showed high stability in hydrogenolysis process in comparison with the commercial carbon based catalysts. Copyright @ 2018 BCREC Group. All rights reserved
\end{abstract}

Keywords: Lignin; Hydrogenolysis; Depolymerization; Biofuel

How to Cite: Shimanskaya, E.I., Stepacheva, A.A., Sulman, E.M., Rebrov, E.V., Matveeva, V.G. (2018). Lignin-containing Feedstock Hydrogenolysis for Biofuel Component Production. Bulletin of Chemical Reaction Engineering \& Catalysis, 13 (1): 74-81 (doi:10.9767/bcrec.13.1.969.74-81)

Permalink/DOI: https://doi.org/10.9767/bcrec.13.1.969.74-81

\section{Introduction}

The depletion of fossil fuels and growing concern about the excessive greenhouse gas emissions led scientists to explore renewable energy sources - abundant and relatively clean alternative to liquid fuels and chemicals produced from petroleum [1,2]. Nowadays, most investigations are focused on the conversion of different types of waste to valuable products. Lignin is positioned as one of the types of industrial solid waste in large quantities produced by wood processing and pulp and paper produc-

* Corresponding Author.

E-mail: shimanskaya-tstu@yandex.ru

(Shimanskaya, E.I)

Telp.: +74-82-2789348; Fax.: +74-82-2789317 tion. According to different reports, the annual world production of lignin varies from 40 to 50 million tons [3-5]. Due to its unique structure, based on the phenolic monomers, lignin can be used as a raw material for a large-scale production of chemicals, including hydrocarbon fuels.

Lignin is difficult to process because of its complex nature and instability that consists of the irreversible changes of the polymer properties during thermal or chemical treatment. At present, lignin is used as a low-grade boiler fuel to provide the process with heat and electricity [6]. However, the chemical structure of lignin suggests that it may be a good source of chemicals if it can be broken down into lower molecular weight units [7]. Current investigations on lignin processing are geared towards its thermal 
degradation (i.e., slow and fast pyrolysis and gasification) $[4,8]$. Besides the combustible gaseous products, thermal methods lead to the formation of so-called bio-oil that poses the complex mixture consisting of phenol derivatives, aromatics, olefins etc. However, the direct use of bio-oil seems to be impossible due to high oxygen content and pure fuel properties (density, ash content, heat value) [9].

Nowadays there is a growing interest in the combined processes of lignin conversion to liquid fuel. One of such processes is hydrogenolysis. Typically lignin hydrogenolysis process bundles both solvolysis and hydrogenation reactions which are conducted in different solvents media (particularly polar) in the presence of metal based catalysts, such as: sulfide CoMo and NiMo supported on activated carbon [3,10], alumina supported platinum catalysts [11], palladium supported on HZSM-5 zeolite [12,13] and ruthenium deposited on $\mathrm{TiO}_{2}$ [14]. The analysis of the literature data showed that the most prospective solvents are propanol [15], ethanol [5,16,17], and toluene [17]. These chemicals allow obtaining high lignin conversion (40-80 \%) producing basically phenolic and aromatic compounds. In this investigation, we report the use of $\mathrm{Pt}$ and $\mathrm{Pd}$ catalytic systems supported on hypercrosslinked polystyrene (HPS) in the process of hydrogenolysis of lignocellulosic feedstock. The polymer based catalysts were compared with the commercial $\mathrm{Pd} / \mathrm{C}$ and $\mathrm{Pt} / \mathrm{C}$.

\section{Experimental}

\subsection{Materials}

Commercial catalysts of $5 \% \mathrm{Pd} / \mathrm{C}$ (Sigma Aldrich, USA) and $5 \% \mathrm{Pt} / \mathrm{C}$ (Sigma Aldrich, USA) were preliminary reduced in hydrogen flow at $300{ }^{\circ} \mathrm{C}$ for 3 hours before the use in hydrogenolysis process. Hexachloroplatinic acid $\left(\mathrm{H}_{2} \mathrm{PtCl}_{6}\right.$, analytical grade, Sigma Aldrich, USA), sodium tetrachloropalladate $\left(\mathrm{Na}_{2} \mathrm{PdCl}_{4}\right.$, analytical grade, Sigma Aldrich, USA), nonfunctionalized HPS as MACRONET-270 (MN270, Purolite Ltd., UK), tetrahydrofuran (THF, chemical grade, ReaChem, Russia), and methanol (chemical grade, ReaChem, Russia) were used for polymer based catalysts synthesis. Anisole (chemical grade, ReaChem, Russia) was used as a model compound for the hydrogenolysis process. Softwood sawdust purchased from the local supplier (Tver region, Russia). Ethanol (96 \%, ReaChem, Russia), propanol-2 (chemical grade, ReaChem, Russia), and distilled water were used as solvents for softwood sawdust hydrogenolysis.

\subsection{Pd and Pt-containing polymer based catalysts preparation}

The HPS with the mean particle size $80 \mu \mathrm{m}$ was preliminary washed with water and acetone and dried in vacuum. Then it was treated with a solution of the calculated amount (5 wt.\% of metal) of metal precursor (hexachloroplatinic acid and sodium tetrachloropalladate) in a complex solvent consisting of THF - methanol - water at room temperature for 10 minutes. Then the resulting catalysts were dried for 40 minutes at $80{ }^{\circ} \mathrm{C}$ and washed by sodium hydrocarbonate aqueous solution and water until the absence of chloride-anion reaction in the scouring waters. The washed catalysts were dried for $90 \mathrm{~min}$ utes at $80^{\circ} \mathrm{C}$ and reduced at $300{ }^{\circ} \mathrm{C}$ by hydrogen for 3 hours.

The synthesized catalysts, as well as the commercial, were characterized using lowtemperature nitrogen physisorption, thermogravimetric analysis (TGA), and X-ray photoelectron spectroscopy (XPS). The methods of the catalyst characterization were described elsewhere [18-20].

\subsection{Model compound hydrogenolysis}

Due to the complex lignin composition anisole as one of the major lignin monomers was chosen as a model compound for the preliminary experiments to determine possible products of lignin-containing material hydrogenolysis. Hydrogenolysis of $30 \mathrm{~mL}$ of anisole was carried out for 4 hours in Parr Series 5000 Multiple Reactor System reactor-cell (Reactor) equipped with a magnetic stirrer in the presence of $0.1 \mathrm{~g}$ of the catalyst at a temperature $250{ }^{\circ} \mathrm{C}$ and hydrogen pressure $1.0 \mathrm{MPa}$. The hydrogenolysis process was conducted at constant stirring $(1700 \mathrm{rpm})$ to eliminate the influence of external diffusion.

\subsection{Hydrogenolysis of softwood sawdust}

The process was carried out for 4 hours in the reactor in a hydrogen atmosphere under the following conditions: substrate weight -1.0 $\mathrm{g}$, catalyst weight $-0.1 \mathrm{~g}$, temperature -250 ${ }^{\circ} \mathrm{C}$, hydrogen partial pressure $-1 \mathrm{MPa}$, solvent volume $-30 \mathrm{~mL}$. The following polar solvents were used: 2-propanol, water, and ethanol. Substrate conversion was calculated at the end of the reaction basing on the difference between the initial mass of the substrate and the dry weight of the residue. 


\subsection{Liquid phase analysis}

Liquid phase samples were taken in all the experiments every 30 minutes. The analysis of the samples was performed using GC-2010 chromatograph and GCMS-QP2010S mass spectrometer (SHIMADZU, Japan). The analysis duration was 25 minutes with the following conditions: initial column temperature of 150 ${ }^{\circ} \mathrm{C}$ was maintained for $5 \mathrm{~min}$, then the temperature was increased up to $250^{\circ} \mathrm{C}$ with the heating rate $5^{\circ} \mathrm{K} / \mathrm{min}$; injector temperature: $280{ }^{\circ} \mathrm{C}$; automatic split; pressure of $\mathrm{He} 53.6$ $\mathrm{kPa}$; common stream of He $81.5 \mathrm{ml} / \mathrm{min}$; linear gas velocity $36.3 \mathrm{~cm}^{3} / \mathrm{s}$; chromatographic column type HP-1MS: $\mathrm{L}=30 \mathrm{~m}$; $\mathrm{d}=0.25 \mathrm{~mm}$; film thickness $0.25 \mu \mathrm{m}$; ion source temperature: 260 ${ }^{\circ} \mathrm{C}$; interface temperature: $280{ }^{\circ} \mathrm{C}$; scanning mode 10 up to $800 \mathrm{~m} / \mathrm{z}$; scanning rate: 1666; electron-impact ionization. The quantitative analysis of sawdust hydrogenolysis liquid products was performed using the method of an internal standard. The quantitative analysis of anisole hydrogenolysis products was performed using the calibration curves.

\section{Results and Discussion}

\subsection{Catalysts characterization}

The summary of the catalysts characterization by low-temperature nitrogen physisorption, XPS and TGA is presented in Table 1. The analysis of the commercial and synthesized catalysts by the method of low-temperature nitrogen physisorption showed that all the studied systems are the mesoporous materials with the narrow slit-like pores. This is confirmed by the IV type of the isotherms with the $\mathrm{H} 4$ type of the hysteresis loop (Figure 1). It is noteworthy that the polymer based catalysts have the higher specific surface area as well as the higher surface area of micropores as compared to the carbon based catalysts (Table 1). All the catalysts studied have the mean pore diameter about $5 \mathrm{~nm}$, however for the polymeric catalysts, the presence of the pores with the diameter $15-20 \mathrm{~nm}$ is observed.

XPS study of the catalysts showed that carbon is the main component on the catalyst surface ( 80 at $\%)$. The trace amounts of $\mathrm{N}, \mathrm{Cl}, \mathrm{Si}$, and $\mathrm{S}(0.5,0.9,0.9$, and 0.5 at $\%$, respectively) were also observed. These elements are the natural surface contaminants absorbed from the air during the catalysts storage. The surface concentrations of the active metals were $1.6,3.0,1.2$, and 2.8 at $\%$ for $5 \% \mathrm{Pd} / \mathrm{C}$, $5 \% \mathrm{Pd} / \mathrm{MN}-270,5 \% \mathrm{Pt} / \mathrm{C}$, and $5 \% \mathrm{pt} / \mathrm{MN}-270$, respectively (Figure 2). The modeling of the highresolution spectra of the catalysts for $\mathrm{Pd} 3 \mathrm{~d}$ and $\mathrm{Pt}$ 4f sublevel showed that the active phase of all studied systems is presented by the mixture of metallic and oxide phases.

Thermogravimetric analysis data of the catalysts samples are presented in Figure 3. On the thermograms of carbon based catalysts (Figure 3a, 3b) no sufficient weight loss peak was observed. The thermograms of HPS based catalysts (Figure 3c, 3d) showed that decomposition of the polymer begins at $450{ }^{\circ} \mathrm{C}$. Thus, the studied catalysts are stable at the reaction temperature.

\subsection{Catalyst testing in anisole conversion process}

Due to the nature of anisole which can be used as a solvent, there was no need to add any solvents while conducting the process and therefore the influence of solvents on the reaction was excluded. The following catalytic systems were used in anisole hydrogenolysis process: synthesized $5 \% \mathrm{Pd} / \mathrm{MN}-270,5 \% \mathrm{Pt} / \mathrm{MN}-270$, and commercial $5 \% \mathrm{Pd} / \mathrm{C}$ and $5 \% \mathrm{Pt} / \mathrm{C}$ to compare the effectiveness of the synthesized cata-

Table 1. Results of catalyst characterization

\begin{tabular}{lcrrc}
\hline Catalyst & $S_{B E T}, \mathrm{~m}^{2} / \mathrm{g}$ & $S_{t-p l o t}, \mathrm{~m}^{2} / \mathrm{g}$ & Binding energy, eV & Metal state \\
\hline $5 \%-\mathrm{Pd} / \mathrm{C}$ & 263.0 & $232.0^{*}$ & $335.1(85.8 \%)$ & $\mathrm{Pd}(0)$ \\
& & $31.0^{* *}$ & $337.5(14.2 \%)$ & $\mathrm{PdO}$ \\
$5 \%-\mathrm{Pt} / \mathrm{C}$ & 297.0 & $232.0^{*}$ & $71.4(63.8 \%)$ & $\mathrm{Pt}(0)$ \\
& & $31.0^{* *}$ & $75.4(36.2 \%)$ & $\mathrm{PtO}$ \\
$5 \%-\mathrm{Pd} / \mathrm{MN}-270$ & 705.0 & $75.0^{*}$ & $335.0(77.5 \%)$ & $\mathrm{Pd}(0)$ \\
& & $630.0^{* *}$ & $337.4(22.5 \%)$ & $\mathrm{PdO}$ \\
$5 \%-\mathrm{Pt} / \mathrm{MN}-270$ & \multirow{2}{*}{691.0} & $83.0^{*}$ & $71.4(59.3 \%)$ & $\mathrm{Pt}(0)$ \\
& & $608.0^{* *}$ & $75.4(40.7 \%)$ & $\mathrm{PtO}$ \\
\hline
\end{tabular}

*surface area of macropores

**surface area of micropores 

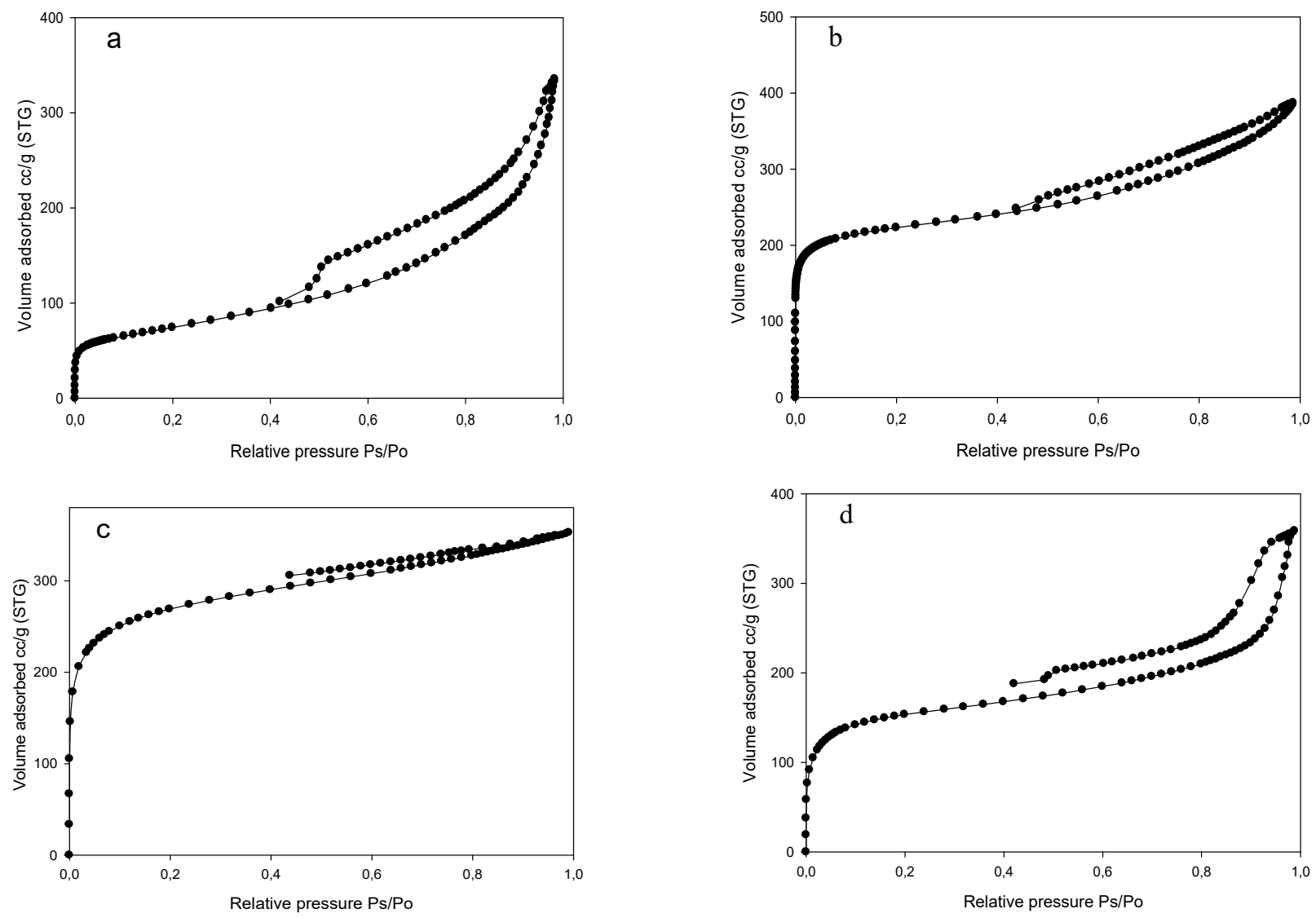

Figure 1. Absorption isotherms for the catalysts: $5 \% \mathrm{Pt} / \mathrm{C}(\mathrm{a}) ; 5 \% \mathrm{Pd} / \mathrm{C}(\mathrm{b}) ; 5 \% \mathrm{Pt} / \mathrm{MN}-270$ (c), and $5 \% \mathrm{Pd} / \mathrm{MN}-270(\mathrm{~d})$
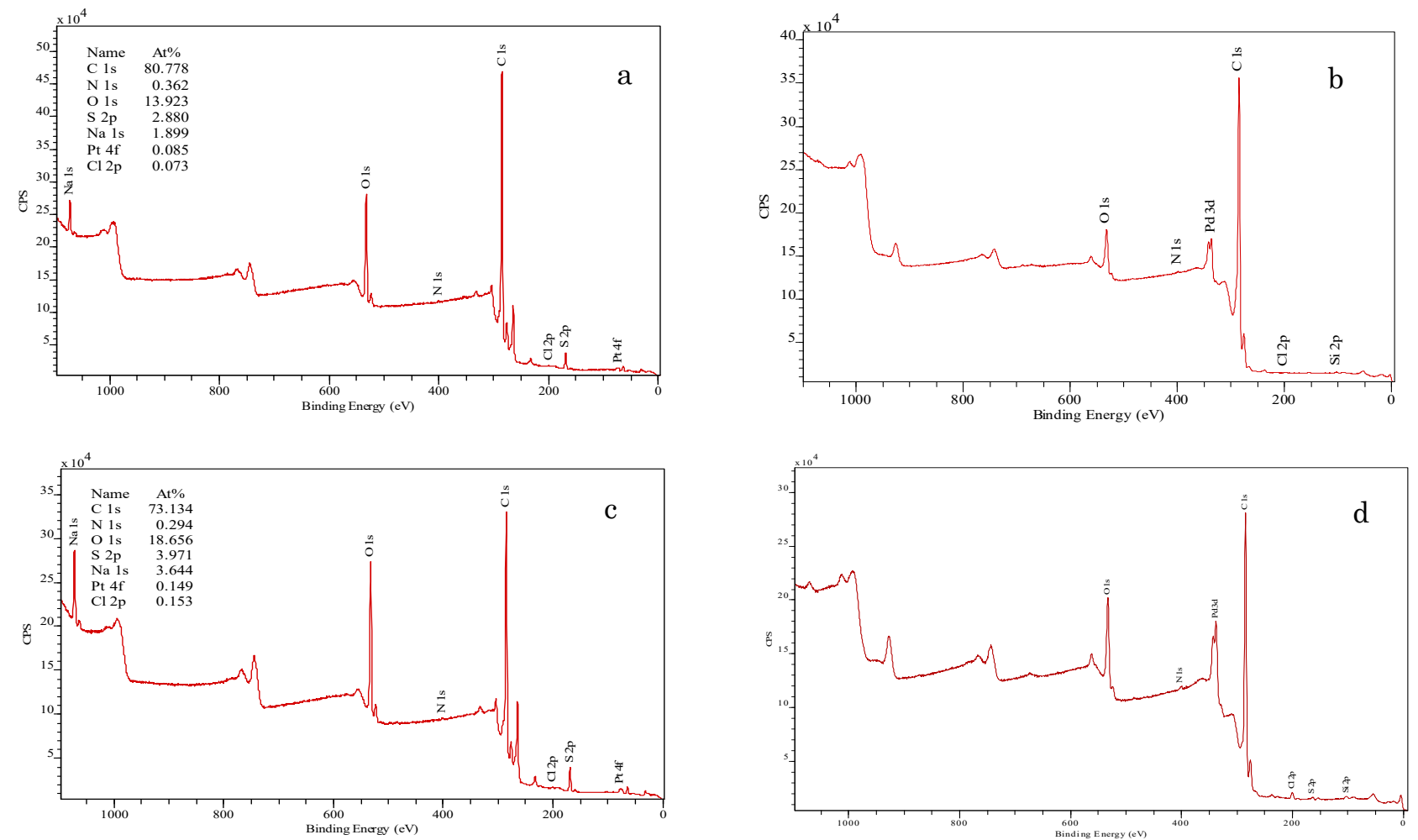

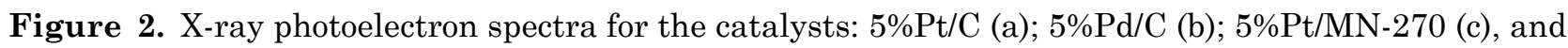
$5 \% \mathrm{Pd} / \mathrm{MN}-270(\mathrm{~d})$ 
lysts. The comparison of the catalyst activity was performed using related rate value at $30 \%$ conversion.

The use of the catalysts on the base of activated carbon and HPS resulted in the formation of cycloalkanes (cyclohexane and methoxycyclohexane) and aromatic compounds (benzene and toluene). Phenol was the other main product of anisole conversion o-cresol and 2,6-xylenol were observed in a trace amount. Cyclohexane was found to be the final product at the highest degree of anisole conversion.
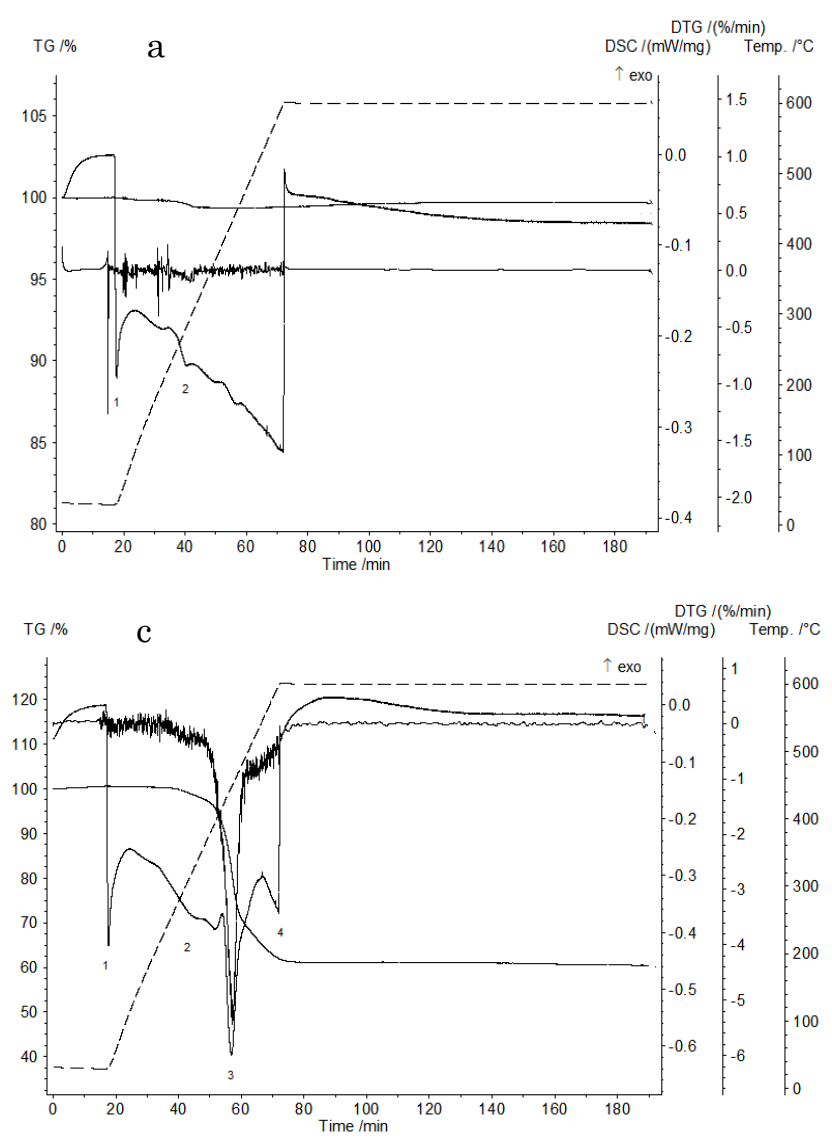

Basing on the data of liquid samples analysis the following scheme of anisole conversion in hydrogen atmosphere can be proposed (Figure 4).

Table 2 represents the results of anisole hydrogenolysis process in the presence of the studied catalysts. All the catalysts used showed the similar values of the related reaction rate $\left(\sim 3.50 \mathrm{~s}^{-1}\right)$ and substrate conversion ( $90 \%)$. However, the polymer based catalysts showed higher selectivity towards the cyclohexane formation as compared with the carbon based catalysts.
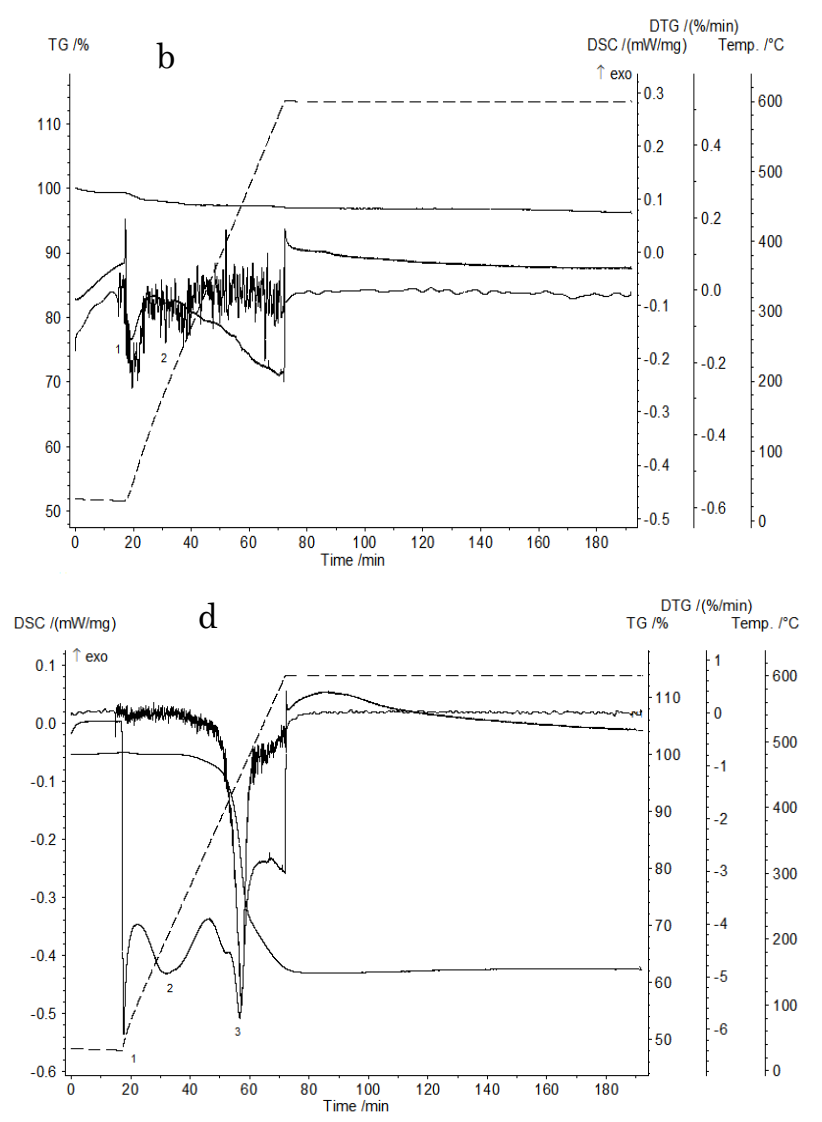

Figure 3. Thermograms of the catalysts: $5 \% \mathrm{Pt} / \mathrm{C}(\mathrm{a}) ; 5 \% \mathrm{Pd} / \mathrm{C}(\mathrm{b}) ; 5 \% \mathrm{Pt} / \mathrm{MN}-270$ (c); $5 \% \mathrm{Pd} / \mathrm{MN}-270$ (d)

Table 2. Results of catalyst testing in anisole conversion

\begin{tabular}{lccc}
\hline Catalyst & $\begin{array}{c}\text { Related rate at 30\% } \\
\text { conversion, } \mathrm{s}^{-1}\end{array}$ & Selectivity, \% & $\begin{array}{c}\text { Conversion at maximal } \\
\text { selectivity, \% }\end{array}$ \\
\hline $5 \%-\mathrm{Pd} / \mathrm{C}$ & 3.47 & $68.9^{\mathrm{a}}$ & 90.1 \\
& & $29.8^{\mathrm{b}}$ & 90.3 \\
$5 \%-\mathrm{Pt} / \mathrm{C}$ & 3.49 & $72.1^{\mathrm{a}}$ & 89.5 \\
& & $27.9^{\mathrm{b}}$ & 89.9 \\
$5 \%-\mathrm{Pd} / \mathrm{MN}-270$ & 3.43 & $87.7^{\mathrm{a}}$ & \\
& & $12.3^{\mathrm{b}}$ & \\
$5 \%-\mathrm{Pt} / \mathrm{MN}-270$ & 3.50 & $9.4^{\mathrm{b}}$ & \\
& & &
\end{tabular}

aregarding to cyclohexane, ${ }^{\mathrm{b}}$ regarding to phenol 


\subsection{Testing of catalytic systems during softwood sawdust hydrogenolysis}

In order to study the solvent influence on sawdust processing, three solvents (ethanol, propanol-2, and water) were used for softwood sawdust hydrogenolysis in the presence of the commercial $5 \% \mathrm{Pd} / \mathrm{C}$. The results of lignincontaining raw material processing in different solvents are presented in Figure 5. The substrate conversion values were $45 \%$ in a water medium, $50 \%$ in propanol- 2 and $37 \%$ in ethanol. As it can be seen from Figure 5 while the hydrogenolysis was carried out in a water medium the highest yield of phenolic compounds was obtained. It can be explained by the higher polarity of water in comparison with the other solvents used. However, we focused on the production of hydrocarbons, thus, depending on the desirable products propanol-2 was chosen as the solvent showing the highest substrate conversion and product yield.

The comparison of the catalytic action of synthesized systems in sawdust hydrogenolysis in the propanol-2 medium is presented in Table

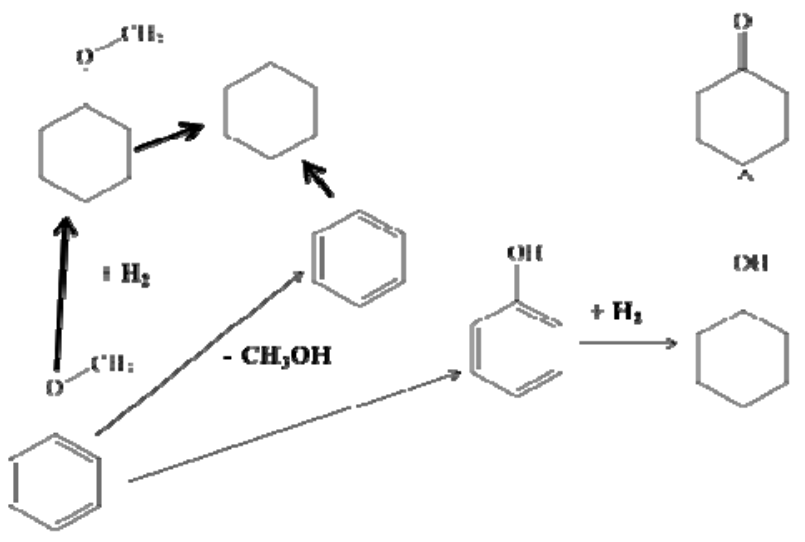

Figure 4. Anisole conversion scheme (continuous thick lines - product formation in the presence of polymer based catalysts; continuous fine lines - product formation in the presence of carbon based catalysts)
3. It is well seen that polymer based catalysts provide higher substrate conversion in comparison with carbon based catalysts. This can be due to the higher surface area and the higher active metal concentration on the catalyst surface. Also, it is notable, that Ptcontaining catalysts result in the lowest formation of oxygen containing products (phenols and methoxycyclohexane). The highest conversion $(68 \%)$ and the highest selectivity towards the oxygen free hydrocarbons (96\%) were achieved while using Pt catalyst based on HPS.

In order to detect the other hydrogenolysis products, the liquid phase was analyzed using HPLC. The analysis showed the presence of mono- and disaccharides as well as the sugar alcohols in the liquid samples obtained during the reaction. These compounds seem to be the products of the conversion of cellulose containing in the sawdust ( 47 wt.\%). It is noteworthy that the yield of aromatic and cyclic products corresponds to the concentration of lignin in the raw material ( $\sim 36$ wt. \%).

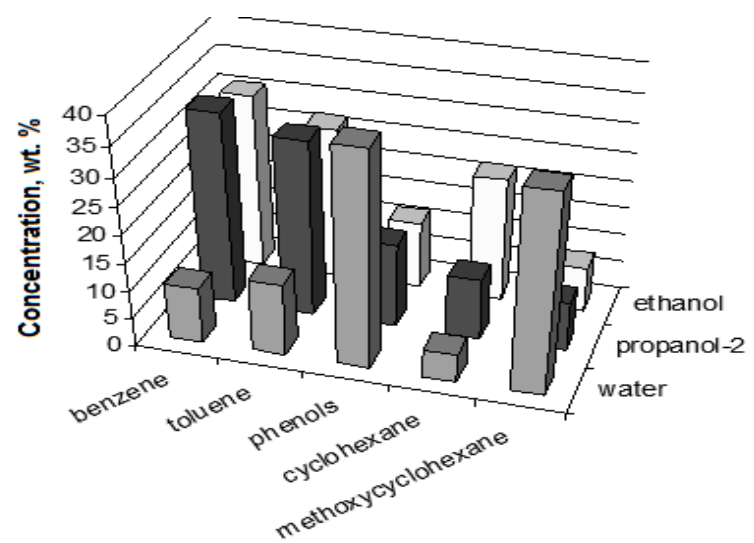

Figure 5. Comparison of the products of sawdust hydrogenolysis in the presence of $5 \% \mathrm{Pd} / \mathrm{C}$ in different solvents

Table 3. Results of catalyst testing in softwood sawdust hydrogenolysis

\begin{tabular}{lcccccc}
\hline \multirow{2}{*}{ Catalysts } & Conversion, \% & \multicolumn{5}{c}{ Product concentration in the liquid phase, wt. \% } \\
\cline { 3 - 7 } & & Benzene & Toluene & Cyclohexane & $\begin{array}{c}\text { Methoxy- } \\
\text { cyclohexane }\end{array}$ & Phenols \\
\hline $5 \%-\mathrm{Pd} / \mathrm{C}$ & 50 & 30 & 27 & 10 & 17 & 16 \\
$5 \%-\mathrm{Pt} / \mathrm{C}$ & 52 & 53 & 21 & 12 & 10 & 4 \\
$5 \%-\mathrm{Pd} / \mathrm{MN}-270$ & 65 & 38 & 22 & 17 & 13 & 10 \\
$5 \%-\mathrm{Pt} / \mathrm{MN}-270$ & 68 & 60 & 18 & 8 & 3 & 1 \\
\hline
\end{tabular}




\section{Conclusions}

Among the products obtained during hydrogenolysis of lignin-containing raw materials fuel-like aromatic and cyclic hydrocarbon (benzene, toluene, and cyclohexane), as well as phenolic compounds are the most promising. The latter can be used as additives to conventional fuels and fuels derived from biomass. Moreover, a number of cyclic and aromatic hydrocarbons may also be used in various fields of fine chemicals production as solvents and reagents.

The use of catalytic systems based on platinum group metals allows obtaining a high yield of valuable products. The comparison of synthesized and commercial catalysts shows that polymer based catalysts allow achieving the higher raw material conversion as well as the higher hydrocarbon selectivity. The highest selectivity towards the oxygen free hydrocarbons $(96 \%)$ at the maximal conversion (68 \%) of lignin-containing material was reached in the presence of $5 \% \mathrm{Pt} / \mathrm{MN}-270$ catalyst. Moreover, the synthesized polymer based catalysts showed high stability in the hydrogenolysis process (up to 5 consecutive cycles without any regeneration).

\section{Acknowledgement}

The authors thank the Russian Science Foundation (grant 15-13-20015) and the Russian Foundation for Basic Research (grant 1808-00609 A) for the financial support.

\section{References}

[1] Yang, H., Yan, R., Chen, H., Lee, D.H., Zheng, C. (2007). Characteristics of Hemicellulose, Cellulose and Lignin Pyrolysis. Fuel, 86: 1781-1788.

[2] Borges da Silva, E.A., Zabkova, M., Araújo, J.D., Cateto, C.A., Barreiro, M.F., Belgacem, M.N., Rodrigues, A.E. (2009). An Integrated Process to Produce Vanillin and Lignin-based Polyurethanes from Kraft Lignin. Chem. Eng. Res. Des., 87: 1276-1292.

[3] Kumar, C.R., Anand, N., Kloekhorst, A., Cannilla, C., Bonura, G., Frusteri, F., Barta, K., Heeres, H.J. (2015). Solvent Free Depolymerization of Kraft Lignin to Alkyl-Phenolics Using Supported NiMo and CoMo Catalysts. Green Chem., 17 (11): 4921-4930.

[4] Li, C., Zhao, X., Wang, A., Huber, G.W., Zhang, T. (2015). Catalytic Transformation of Lignin for the Production of Chemicals and Fuels. Chem. Rev., 115 (21): 11559-11624.
[5] Patil, P.T., Armbruster, U., Richter, M., Martin, A. (2011). Heterogeneously Catalyzed Hydroprocessing of Organiosolv Lignin in Suband Supercritical Solvents. En. Fuels, 25: 4713-4722.

[6] Huber, G.W., Iborra, S., Corma, A. (2006). Synthesis of Transportation Fuels from Biomass: Chemistry, Catalysts, and Engineering. Chem. Rev., 106: 4044-4098.

[7] Kamm, B., Kamm, M. (2004). Principles of Biorefineries. Appl. Microbiol. Biotechnol., 64: 137-145.

[8] Bozell, J.J. (2014). Approaches to the Selective Catalytic Conversion of Lignin: A Grand Challenge for Biorefinery Development. Top. Curr. Chem., 353: 229-255.

[9] Bulushev, D.A., Ross, J.R.H. (2011). Catalysis for Conversion of Biomass to Fuels via Pyrolysis and Gasification: A Review. Catalysis Today, 171: 1-13.

[10] Horácek, J., Homola, F., Kubicková, I., Kubicka, D. (2012). Lignin to Liquids over Sulfided Catalysts. Catalysis Today, 179: 191-198.

[11] Saidi, M., Rahimpour, M.R., Raeissi, S. (2015). Kinetics of Upgrading of Anisole as a Lignin-Derived Bio-oil with Hydrogen Catalyzed by Platinum Supported on Alumina. En. Fuel, 29: 3335-3344.

[12] Jan, O., Marchand, R., Anjos, L.C.A., Seufitelli, G.V.S., Nikolla, E., Resende, F.L.P. (2015). Hydropyrolysis of Lignin Using Pd/HZSM-5. En. Fuel., 29 (3): 1793-1800.

[13] Bi, P., Wang, J., Zhang, Y., Jiang, P., Wu, X., Liu, J., Xue, H., Wang, T., Li, Q. (2015). From Lignin to Cycloparaffins and Aromatics: Directional Synthesis of Jet and Diesel Fuel Range Biofuels Using Biomass. Biores. Technol., 183: 10-17.

[14] Kloekhorst, A., Heeres, H.J. (2015). Catalytic Hydrotreatment of Alcell Lignin Using Supported $\mathrm{Ru}, \mathrm{Pd}$, and $\mathrm{Cu}$ Catalysts. Sust. Chem. Eng., 3 (9): 1905-1914.

[15] Ferrini, P., Rinaldi, R. (2014). Catalytic Biorefining of Plant Biomass to Non-Pyrolytic Lignin Bio-Oil and Carbohydrates through Hydrogen Transfer Reactions. Angew. Chem. Int. Ed., 53: 1-7.

[16] Huang, X., Koranyi, T.I., Boot, M.D., Hensen, E.J.M. (2014). Catalytic Depolymerization of Lignin in Supercritical Ethanol. Chem Sus Chem., 7: 2276-2288.

[17] Murnieks, R., Kampars, V., Malins, K., Apseniece, L. (2014). Hydrotreating of Wheat Straw in Toluene and Ethanol. Biores. Technol., 163C: 106-111. 
[18] Sapunov, V.N., Stepacheva, A.A., Sulman, E.M., Wärnå, J., Mäki-Arvela, P., Sulman, M.G., Sidorov, A.I., Stein, B.D., Murzin, D.Yu., Matveeva, V.G. (2017). Stearic acid Hydrodeoxygenation over Pd Nanoparticles Embedded in Mesoporous Hypercrosslinked Polystyrene. J. Ind. Eng. Chem., 46: 426-435.

[19] Doluda, V.Yu., Sulman, E.M., Matveeva, V.G., Sulman, M.G., Bykov, A.V., Lakina, N.V., Sidorov, A.I., Valetsky, P.M., Bronstein, L.M. (2013). Phenol Catalytic Wet Air Oxidation Over Ru Nanoparticles Formed in Hypercrosslinked Polystyrene. Top. Catal., 56: 688695.
[20] Nikoshvili, L., Shimanskaya, E., Bykov, A., Yuranov, I., Kiwi-Minsker, L., Sulman, E. (2015). Selective Hydrogenation of 2-methyl3-butyn-2-ol over Pd-nanoparticles Stabilized in Hypercrosslinked Polystyrene: Solvent Effect. Catalysis Today, 241, Part B: 179-188. 